\title{
THE PREMENSTRUAL DEFENCE
}

\author{
DR CAROLINE HENAGHAN, BASED AT THE UNIVERSITY OF MANCHESTER \\ IN THE UK, IS TAKING A SOCIO-LEGAL AND INTERDISCIPLINARY \\ APPROACH TO THE PROBLEMS ASSOCIATED WITH PREMENSTRUAL \\ DYSPHORIC DISORDER. THE FINDINGS WILL HELP DEVELOP \\ UNDERSTANDING OF - AND APPRECIATION FOR - THE RELATIONSHIP \\ BETWEEN THE FEMALE MENSTRUAL CYCLE AND MENTAL HEALTH
}

\section{TALK LIKE A \\ LEGAL RESEARCHER}

APPELLANT - a person appealing against a court's decision

AUTOMATISM - a defence which holds that a person cannot be considered as responsible for their actions

DEFENDANT - the accused person in a court of law

DEFENCE - the response given by the defendant to excuse or justify their criminal actions

\section{DIMINISHED RESPONSIBILITY -} when a defendant cannot be seen as fully responsible for their actions because of the impact a recognised medical condition has on their mental capacity

EXPERT WITNESS - a person with expert knowledge or skills in a particular field who testifies in court

INSANITY - when a defendant is considered unable to understand their actions
Premenstrual dysphoric disorder (PMDD) is a health problem that is often compared to premenstrual syndrome (PMS) but is more serious. The condition typically occurs in women in the week or two before their period starts when hormone levels start to fall after ovulation. PMDD can cause a wide range of symptoms, ranging from severe depression to irritability and anxiety.

Dr Caroline Henaghan, who is based at the University of Manchester in the UK, had PMDD for several years before she realised that her problems with anxiety and depression were connected to her menstrual cycle. After conducting her own research into PMDD and PMS, she found out about a doctor called Katherina Dalton who, alongside another clinician called Raymond Greene, had originally coined the term premenstrual syndrome (what we now know as PMS) in 1953.

However, as a lawyer, what most interested Caroline was that Katherina had appeared as an expert witness in a number of murder trials in the 1980s, where she had given evidence that allowed three different female defendants to plead a defence of diminished responsibility on account of their PMS symptoms. This is what led to Caroline's ongoing interest in 'the premenstrual defence' which forms the basis of her current research.

\section{PMDD - A MEDICAL DISORDER}

Somewhat remarkably, it was not until 2013 that PMDD was listed as a mental health problem. On the other hand, there is a long history of society and culture attaching prejudice, stigma and shame to the female menstrual cycle.

Consider the fact that it was only in 2021 that the 'tampon tax' was abolished - before then, menstrual products were considered luxury items and were taxed as such! We often consider that we live in a civilised society, but when faced with the idea that tampons are luxury items, it is easy to see how far we still have to go. However, the abolition of the tax shows that we are headed in the right direction, albeit slowly.

\section{THE LEGAL POSITION OF THE} PREMENSTRUAL DEFENDANT

The key idea behind the premenstrual defence is that a woman's behaviour, mood and actions can be driven by PMDD and, therefore, a greater degree of understanding of this should be shown when the woman is charged or sentenced. However, as it stands, there is no such thing as a premenstrual defence. "A defendant who 



\section{ABOUT LAW}

As Caroline's career has shown, a law degree does not necessarily have to lead to becoming a barrister or solicitor. Caroline's background as a qualified lawyer has stood her in good stead and informed her current research, but having an interest in the social aspects of law - and, in this case, the position of women in society are equally important.

\section{WHAT DOES CAROLINE FIND} REWARDING ABOUT RESEARCH IN HER FIELD?

Caroline is quick to point to her love of the 'social' aspect of her socio-legal research.

"The bits of what I am doing that I know have the potential to exert a powerful impact on people's lives are the best. For example, making a contribution to re-thinking the current English criminal law defences, which have been in existence for years and years," says Caroline. "Although my research might only play a small part in any change that does come about, it is rewarding to know that l've been involved in that reform. Just as it is rewarding to have the opportunity to be involved in this project and tell everybody a bit more about my research!"

\section{WHAT ISSUES WILL FACE THE NEXT} GENERATION OF LAW ACADEMICS?

Caroline thinks that law academics will need to address very similar issues to other academics. In a post-COVID world, where technological advances and ways of working are changing all the time, a period of adjustment is going

\section{EXPLORE CAREERS IN LAW}

- If you want to train as a barrister as Caroline did, you should visit the Bar Council website, particularly the 'becoming a barrister' section: www.barcouncil.org.uk/becoming-a-barrister.html

- Alternatively, if you are aiming to become a solicitor, you should take a look at the Law Society website and the 'becoming a solicitor' section: www.lawsociety.org.uk/career-advice/becoming-a-solicitor/

- Technically, there is no official minimum salary for trainee lawyers, however The Law Society recommends a minimum of £22,794 for those training in London and £20,217 for trainees elsewhere in the country. You can earn substantially more once you are qualified and more experienced.

\section{CAROLINE'S TOP TIPS}

01 Find out what you enjoy doing and try to build a career around the things you are really passionate about.

02 I know it is a cliché, but if at first you don't succeed then try and try again - so much of science is failing initially, but perseverance will get you to where you want to be.

03 Try and enjoy the ride. When times get tough (and they will), take a step back and think about why you began doing what you are doing. It will all be worth it in the end! 


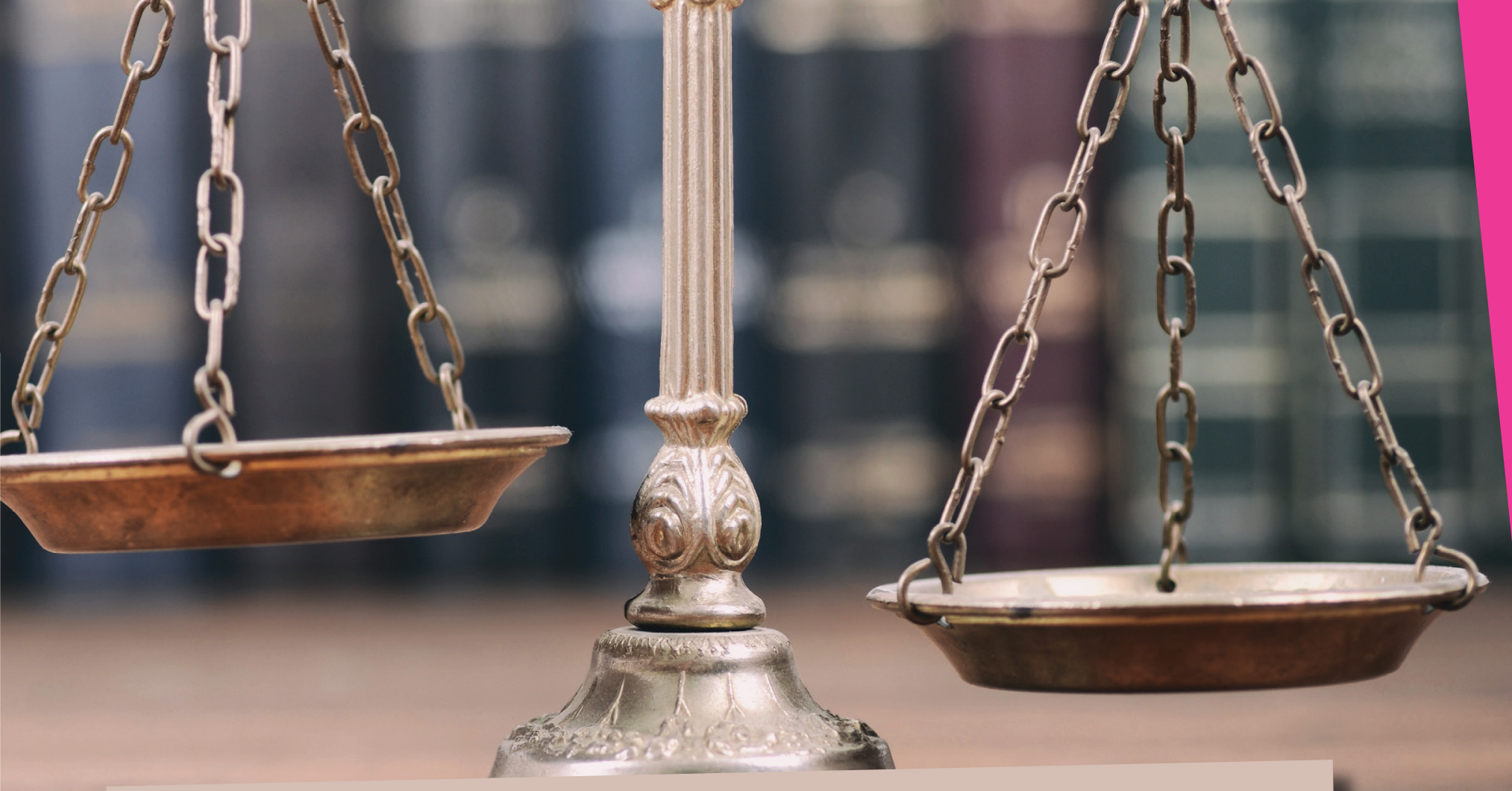

\section{HOW DID CAROLINE BECOME A LEGAL RESEARCHER?}

WHAT WERE YOUR INTERESTS WHEN YOU WERE GROWING UP?

Reading! I am an only child and I'm afraid that I'm also a bit of cliché. My head was always in a book when I was growing up, so nothing much has changed there!

WHO OR WHAT INSPIRED YOU TO PURSUE LAW?

My dad - but he was a carpenter, not a lawyer. One day, when I was eight years old, my dad was called up to do jury service. He came back and told me all about his experience of going to court. I was hooked and I haven't looked back since. Along the way, I have met many others who have given me the inspiration to keep going. But that first spark of interest came from my dad's stint as a member of a crown court jury.

WHAT ATTRIBUTES HAVE MADE YOU SUCCESSFUL IN YOUR CAREER?

Adaptability. Life can often be a series of lots of different challenges. But what is it they say? 'Every problem is an opportunity in disguise'. I have had a few different roles in my career and, for me, being able to adapt has been key to my success in all the different things I've done. Something that l've learned more recently just have a go! Whatever it is, even if I don't think I stand a chance, I try to have a go. You never know your luck when you try something new. And if you're not always successful in whatever it is you're having a go at, it will still be a good learning curve in any event.

\section{HOW DO YOU OVERCOME}

OBSTACLES AND SWITCH OFF FROM YOUR WORK?

Persistence is key to how I overcome any obstacles I might face. I don't always get things right first time - nobody does! But if I keep reminding myself to keep on going, I'm bound to get there in the end. That's my philosophy. And walking is the best way for me to get myself away from the screen and switch off from work. Doesn't matter where I am - the rhythm of walking along helps me to slow down and unwind.

WHAT ARE YOUR PROUDEST CAREER ACHIEVEMENTS SO FAR?

Finishing my PhD! That was the culmination of an awful lot of hard work (and obviously, it means that I now get to be called $\mathrm{Dr}$ Henaghan). But, also, because it marked the end of a long journey with my own PMDD. One year after I started the $\mathrm{PhD}$, I underwent surgery for my condition. Without that operation, I am not sure that I would be in the position I am today, or that I would have been able to complete my PhD. That's my proudest achievement so far. Hopefully, there will be more to come...

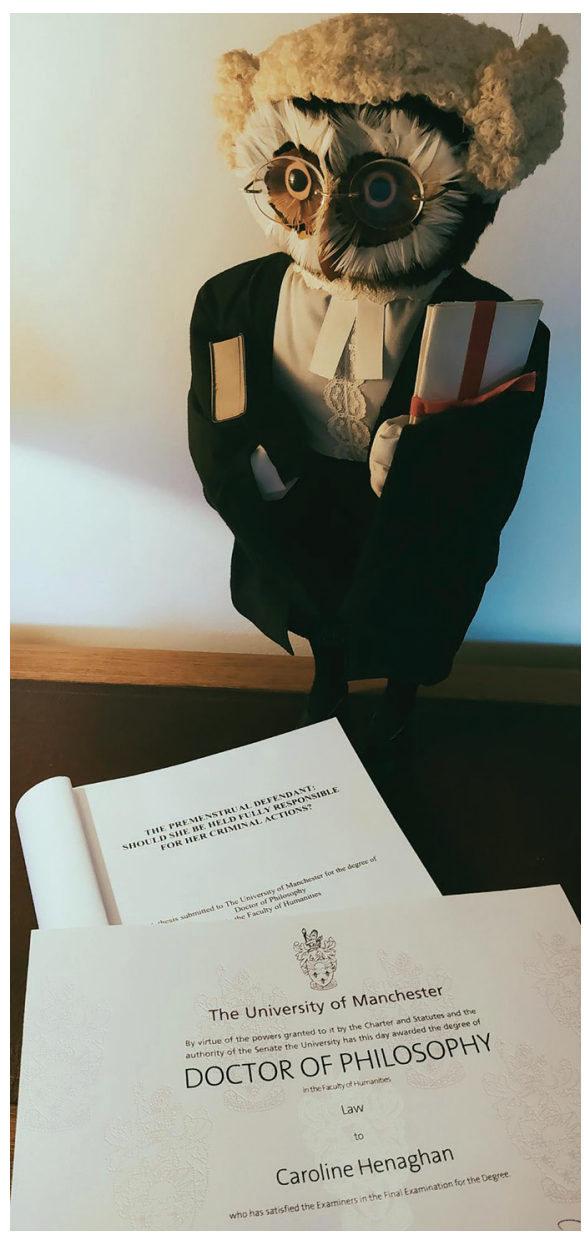

The title page of Caroline's thesis and her $\mathrm{PhD}$ certificate 